\section{THE HUNTERIAN ORATION}

\section{FOR I87I.}

\section{Delivered at the Royal College of Surgeons of England, February I4th, I87 I.}

BY SIR WILLIAM FERGUSSON, BART., F.R.S., President of the College, and Serjeant-Surgeon to the Queen.

Mr. President and Gentlemen, - We are met to commemorate the hundred and forty-second anniversary of the natal day of John Hunter.

Although Hunter's death, which occurred in I793, was lamented, owing to its tragic character, and the prominent position he held as a surgeon and man of science, there was a somewhat tardy recognition of those great qualities for which he has been subsequently eulogised. There were varied opinions among his contemporaries and survivors ; and, for seven years afterwards, it seemed doubtful what might become of the palpable remains of his life-long labours in science and surgery. The chief of these, his museum and manuscripts, were in confusion; and there was great danger that they might be so scattered and subdivided that the grand objects of his researches might never have been comprehended. Happily, through the sound judgment of his executors, and the enthusiasm of an apprentice boy, William Clift, the precious relics were held together until purchased as a whole by the Government, and finally placed under the care of this College. In the year 1800 the collection first came under the protection of the Royal College of Surgeons. The proved abilities of young Clift were still devoted to its service; but considerable time elapsed before it acquired more than a beginning to the great reputation subsequently attached to it.

The absence of proper catalogues seems to have been much felt. Hunter had delayed this part of his work, doubtless trusting to leisure time in later years. A gentleman, who might be considered equal to Clift himself in knowledge of the contents and characters of both, undertook the duty, and for that purpose had the manuscripts removed, for convenience, to his own residence. A cartload-literally a cartload- of these was taken possession of, but never again saw the light of day. Years rolled on ; trustees, Council, and Mr. Clift alike failed to regain possession of the papers, or of the semblance of a catalogue. At last, in 1823 , it was announced that these papers had been commit ted to the flames ! It was not until 1813, and after much expense, towards which Parliament liberally contributed, that the Museum was open for public inspection.

Catalogues have been prepared under most proficient skill; the Council has spared neither pains nor expense to enhance its character and at this date it is indisputably the finest of its kind in the world. The progress of increase seems never to cease ; year after year large acquisitions are made by purchase and from donations; and since we last met on an occasion like the present, a collection specially illustrative of dermatology has been added, by the munificence of a member of our Council, which augments in a remarkable degree the value of the whole.

About twenty years after Hunter's death, two of his connexions and most distinguished pupils, Dr. Matthew Baillie and Sir Everard Home, made arrangements for the permanent commemoration of his birthday, and since the year 1813 a ceremony like the present has, with few intermissions, taken place. A member of the Council of this College is required by the terms of the deed of arrangement to pay tribute to Hunter's memory, and to make passing record of recently deceased members of our profession, whose deeds in life may have had association with the works in which Hunter himself had been interested.

Seventy-seven years have elapsed since the death of Hunter, and his memory is at this date cherished in a greater degree than it was sixty, or even forty, years ago. In the progress of time his works have become more and more appreciated, and with all familiar with them the impression increases in force, that he has left indications of industry and intellect such as have rarely been associated in one individual. In addition to his great Museum, portions of his writings have carried his reputation far beyond the sphere in which that collection is placed, and it is interesting to consider on which his future fame will most depend.

It was specially characteristic in Hunter so to associate the labours of head and hand that it may with many be difficult to determine in which he most excelled. A glance at his museum fills the mind with wonder that it should have been the work of one man. The few volumes of his collected writings seem small in proportion; but before coming to a conclusion, the contents of each volume, the quality and original thought contained in that small compass, should be well considered ; and if, in addition, the enormous quantity of manuscript which he left be taken into the estimate, hesitation may arise in deciding as to the field in which his labour was greatest. The proofs on behalf of his pen, now extant, are small in comparison with the mass of papers unhappily destroyed, including the famous ten folio volumes so much lamented by Mr. Clift. When that gentleman was examined on the subject in 1834, by a Committee of the House of Commons, he enumerated a list of papers and treatises, so extensive in number, and so rare and original in quality, that apparently there had been destroyed much more than enough to have founded an imperishable name and reputation in science and natural history.

It has been rare amongst physicians and surgeons, considering the numbers of eminence who have flourished, to leave long-standing memorials of their greatness. Their works of skill and art have perished with themselves in a generation. Great statesmen, architect=, engineers, and painters have left enduring palpable proofs of their qualities, and they are known to fame almost solely by such proofs. No writings remain to attest their scientific skill, or to diffuse their individual knowledge to mankind.

It would be too much to expect at this date palpable memorials, such as I refer to, of Hippocrates or Galen; but to come to more recent times, since the study of anatomy has been zealously pursued, how small is the number of great men in our profession whose fame can be traced otherwise than in association with written works. History is quiet regarding any preparations left by Mundinus, the founder of systematic anatomical teaching. No evidence remains of the hand-labour of Vesalius, Albinus, Cheselden, Cowper, and a host of the bygone great. Only a few proofs of William Harvey's dealings in anatomy are preserved in the College of Physicians of London. Happily, the greater part of Ruysch's celebrated first collections is still, I believe, in good condition in St. Petersburg.

The industry of Ruysch as anatomist and writer was marvellous ; but our English anatomist had a shorter life by a quarter of a century; and, all things considered, there has probably been no such combination of work in one man as that centred in John Hunter. There may have been more voluminous writers in so far as printed works attest, but the untoward fate of his manuscripts must be borne in mind. In respect of work, in the development of a great museum, it may be fairly said that he stands unequalled; and in the combined qualities of writer and practical anatomist, he is alone in a field where a competitor cannot be named.

It is not, however, in mere industry that Hunter's position is to be estimated. There was an originality of thought and action in all that he did which put him far above the rank of ordinary men in his own department of science. His Museum was not a rambling collection of curiosities in natural history, anatomy, and pathology. It was specially designed to illustrate his own favourite pursuits : the study of life in all its phases ; its causes, nature, and development, from the lowest stage of organisation up to the complex structure of man-from the seeds of vegetables to the eggs of animals - from vegetable sap up to human blood and its products.

An anecdote related by Sir Benjamin Brodie in the Hunterian Oration for 1837 is indicative of Hunter's originality and scope of observation. Sir Benjamin says : "When I was formerly giving lectures as professor of this College, I found in a drawer in the Museum what appeared to be some pieces of dried sticks. Mr. Clift said that he did not know what they meant, but he was sure that they meant something, and therefore he had preserved them. When I examined them, I found that they were the result of some interesting experiments in vegetable physiology. It appeared from one of them that he had made the first and most important of the experiments made many years afterwards by Mr. Andrew Knight, proving the descent of the sap through the vessels of the bark. Yet these specimens had no ostensible place in the Museum, and they, would have been swept away as rubbish but for the

Many illustrations of a like kind might be collected to show how Hunter was ahead of his time; and the conviction is strong that, had his manuscripts been preserved, the value and originality of his museum labours would have been greatly enhanced.

Happily for the character of Hunter and his Museum, the silent testimonies of many of his labours have been admirably deciphered by those who have had the principal care of the preparations. It was, indeed, fortunate that Clift should have devoted his life-labour on behalf of his master's works and fame. Equally fortunate was it that such a man 
as Owen should have appeared on the scene so opportunely. Nor should the zeal, talent, and industry of Stanley, Quekett, Paget, Morris, Taylor, Wilson, and others be forgotten in association with Hunter's Museum. To all these gentlemen is chiefly due the merit of those compendious catalogues which throw so much light on Hunter's works and thoughts. It is, in addition, gratifying that the collection is at present under the curatorship of one distinguished alike as anatomist, surgeon, and naturalist, whose work already done gives anticipation of a glorious further career, that shall place his name in association with the Hunters and Cuviers of bygone years.

Few have thought seriously of the time, labour, and expense of developing museums in association with our profession. It seems doubtful if there was any collection in this country worth speaking of prior to the time of the two Hunters. All the senior part of my professional hearers must remember how, in their earlier days, there was a kind of fashion in regard to the formation of museums. Everyone who devoted himself to teaching anatomy, medicine, or midwifery, set his heart upon such work, and some may have lively and possibly peculiar feelings in regard to the labour, time, and money expended. Happily, by the modern system of aggregation of teachers into schools, such custom has fallen into abeyance. Instead of individual exertion, the effort is made by the whole school, and wealth in this way, pecuniary and scientific, has gradually been accumulated, which only the Hunters could have appreciated.

It is said that William Hunter's collection, now belonging to the University of Glasgow, was made at the cost of one hundred thousand pounds. John Hunter's is said to have cost seventy thousand. Through the apathy of a British Minister, who thought that shot and shell were, at the time, of more value to the country than anatomical and pathological specimens, the collection of William Hunter was refused a home in the locality where it had been made. At a subsequent date better feeling prevailed in regard to the younger brother's great works. The purchase-money paid by Government was small compared with the original outlay; but Parliament has again and again responded liberally to appeals for pecuniary aid to extend the buildings for the accommodation of the Museum; and the Royal College of Surgeons of England, dependent solely upon its popularity with the profession and the public, has been enabled so to cherish the original collection of Hunter, so to add to it, and so to associate it with accessories and adjuncts, particu-

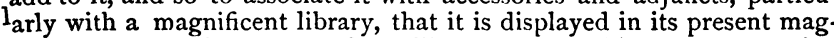
nitude at a cost of a quarter of a million sterling. This grand possession may be said to be the property of the surgical profession and of the public of England. The trustees, and the Council of this College, are its guardians appointed by law. It is freely open, under reasonable regulations, to all comers, of all quality ; and an enthusiast might say, with truth, that it is the heart and soul of British surgery.

Without discussing minutely whether Hunter's future fame will depend chiefly on his Museum or on his printed works, it may be admitted that he is most extensively known by the latter. It is the lot of few, comparatively, to have it in their power to visit the Museum, but his writings extend over the earth, and his doctrines may be said to constitute a large portion of the science of the best practical surgery of the day.

There are mysteries in nature which Hunter did not pretend to explain; and it might be well if some modern philosophers held in mind that the result of life-long study should not be disturbed by the passing idea of a moment, or by the reckless ambition of upsetting or ignoring doctrines emanating from a brain wherein thought had, for more than forty years, assumed a favourite place.

Of all Hunter's printed works, the treatise on the Blood and Inflam. mation is generally admitted to be the most profound. To my mind, there are no parts so replete with interest as those devoted to Development and Absorption. Yet these, if not forgotten, have been well-nigh smothered in modern verbiage. Separate centres of life, new formations and growths, arrestments and changes of action, irrespective of blood and circulation, are among the fashionable doctrines of the day. "Molecular disintegration" now takes the place of Hunter's "disjunctive absorption." Crude statements about veins doing what Hunter described as being done by absorbents-doing what he positively showed by experiment that they could not ; about pus circulating in the blood ; about secondary deposits (as they are called) being the direct result of primary deposits, - ignoring the power of nature to make another, and yet another, deposit when she has already made one; rough experiments which have no semblance to nature's actions ; modern methods of accounting for malignant disease in various distant parts of the body, as being secondary deposits; are among the recent ways of tampering with the beautiful and philosophic views of Hunter.

A great living philosopher, one who is specially great in facts, has suggested that when the microscope fails to detect the elementary par. ticle, imagination may legitimately be permitted to bridge the gap, and mentally extend our vision. But such philosophy is, after all, far from being new. Shakespeare speculated with imaginary histology. $\mathrm{He}$ makes Hamlet, at a prior date, deal with it, as thus :- "Why may not imagination trace the noble dust of Alexander till he find it stopping a bunghole?" Or, again, "Imperial Cæsar, dead and turned to clay,

If imagination is to be a future legitimate course in this direction, let $u s$ imagine something more noble for the "dust" of our hero than the "base uses" to which that of Alexander, or of Casar, was consigned by Hamlet.

If I have this, in good humour, and, I hope without offence, ventured to question the superiority of certain modern doctrines over those of Hunter, yet I do not fail to bear in mind how little will occasionally arrest or turn aside the tide of events in our profession. The current is naturally slow and easily obstructed. More than half a century elápsed ere Davy's suggestion regarding anæsthesia in surgical operations was carried into effect. The progress of ovariotomy was retarded for full thirty years by a simple song of local and personal humour. Who can say what may have been the influence of the sarcastic wit of Rabelais, of Butler, and of John Bell on the doctrines of Taliacotius? Du Hamel and John Hunter were the great animal transplanters (if I may so call them) of their days. Here are the celebrated preparations, from Hunter's own hands, of cocks' spurs and human teeth, taken from their natural locality, flourishing in the cock's comb. Death abruptly cut short Hunter's surgical career ; but may we not claim for him, with all deference and honour to Reverdin, Pollock, and others of the day, that he anticipated by a hundred years, the scientific data on which the present system of human grafting or transplanting is conducted? Here [pointing to a picture] is a representation of portions of skin, each, originally, not bigger than a pin's-head, taken from what Butler would have called the "brawny" part of a boy's arm, flourishing on an ulcer of the leg of an old lady above sixty! What would John Bell, were he now alive, say to this?

But time warns me that I have still other duties to perform within the hour, when my allotted task must be accomplished.

The grave has recently closed over the mortal remains of James Wardrop, Sir William Lawrence, Joseph Hodgson, Sir James Young Simpson, and James Syme. It has seldom happened that so many distinguished men have had claims for notice on occasions similar to this.

James Wardrop possessed great natural abilities, and was an original thinker and actor. His essays "On the Morbid Anatomy of the Human Eye" were much esteemed in their time, and his "Observations on Fungus Hæmatodes," published at an early period of his career, forms to this day the standard work, I may say the only one, on the subject worthy of special note. Some of his published didactic lectures were models of power and simplicity, and his last great work, "On Diseases of the Heart", evinced the sagacity acquired by experience and age-a simplicity of practice, and a reliance on nature, which might be expected from a Hunterian disciple. The fact that he was the first surgeon in England who, after the example of Dupuytren, removed a tumour in the lower jaw by total vertical section of the bone, places his name on the list of high-class practical surgeons ; and his modification of Brasdor's operation, his original distal operations, and the effect that all have had on this department of practice, bring his name in association with Hunter's as closely as that of any other in the history of British surgery.

Of Sir William Lawrence it seems almost a work of supererogation to speak in this theatre. His intellectual head and brow, expressive features, and manly form, can never pass from the remembrance of those who saw him in his prime. A pupil of Abernethy, and an admirer of Hunter greater than his master, if that were possible, he, of all English surgeons, excelled the most in developing the labours of Hunter in comparative anatomy. The currency which he gave in England to the works of Blumenbach ; the taste, eloquence, and ability with which he inculcated the study of comparative anatomy-a subject little more than in its infancy in Lawrence's early days ; his mental capacity as anatomist, scholar, and orator; his polemical energy in supporting his favourite views, whether these were scientific or medico-political, marked him in early years as one of the foremost men of the day in the walk of life which he had chosen. He rose, as we all know, to the highest honours to which a surgeon can aspire in this country ; but it has often been said, and assented to, that, had he been a member of another profession, he might have risen to the highest rank which a subject in England can reach. His treatise "On Hernia," originally a Jacksonian prize essay, may be considered as the first compendious work on this most important subject which ever came from British surgery; and, although published more than sixty years ago, may, in its fifth edition, be considered the standard of reference at the present day. His treatises " $n n$ Diseases 
of the Eye" gave him great and well-grounded reputation in ophthalmic surgery. His "Introduction to Comparative Anatomy and Physiology," and his "Lectures on Physiology, Zoology, and the Natural History of Man," added largely to his fame in early life. His position as surgeon to the greatest of English hospitals with which our profession is in alliance, his acquirements, his oratorical powers, his repute with the profession and public at large, all made him a man of great note. It gives me much pleasure to state that, on some familiarity with the Hunterian orations that have been delivered in this theatre, the two specially devoted to the subject by Lawrence seem to me among the most eloquent which the occasion has ever called forth.

Joseph Hodgson received a considerable part of his education under Abernethy and Lawrence. He distinguished himself in early life by his treatise on the Diseases of the Arteries and Veins, containing the pathology and treatment of aneurisms and wounded arteries. The work, which in its first stage had secured the Jacksonian prize, was more elaborate than any that had appeared since the Hunterian doctrines on the subject had been recognised and approved. It was comprehensive and practical. The language and composition simple and easily understood. It was much esteemed at the time, having been translated into German and French; and it forms a worthy companion to the first-class treatises on surgical subjects which have come from many of his contemporaries-such as Scarpa, Astley Cooper, Charles Bell, Brodie, Samuel Cooper, Travers, Colles, Guthrie, Porter, and numerous others. Mr. Hodgson commenced professional life in London, but soon after was induced to settle in Birmingham. In the ex tensive opportunities afforded for practice in that populous town and surrounding district, he acquired the esteem and confidence of the public and his professional brethren; and for many years no man among the surgeons of Britain was held in greater respect. After a most successful career, he withdrew from the scene of his active labours, and settled in London in dignified retirement. His mind still clung with fondness to the subjects with which it had been most engrossed, and for years his opinion was eagerly sought by his admirers in the profession and among the public. So highly was he esteemed by the Fellows of this College that he was elected to a seat at the Council Board, and in due time placed by that Board on the Court of Examiners. It must be in the recollection of many here how zealously, honestly, and ably he performed all the varied and often most onerous duties pertaining to such distinctions, and also how gracefully he filled the presidential chair before finally retiring from public life. It was his fortune to be a Hunterian orator. Few others more clearly and zealously appreciated the Hunterian philosophy; and it was a pleasing combination of circumstances which finally brought him out in that character, after he had been long recognised as the chief authority on the operation with which Hunter's name is indelibly associated.

The name of Sir James Young Simpson is deeply impressed on the history of medicine and surgery. His example is one among many in our profession, as well as in others, of what may be called a self-made man. Possessing even fewer advantages than most beginners in life, his individual industry made up the deficiencies. He rarely, if ever, neglected an opportunity of acquiring knowledge. He worked in schoolboy days whilst others played. In early professional life he attracted the notice of Dr. John Thompson, the able expounder of Hunter on Inflammation, and was selected by that distinguished man as a special assistant. The scientific atmosphere in which Thompson lived must have had great influence on Simpson's youthful, I may say latent, talent. The connexion, I have no doubt, went far to favour his claim for the chair of Midwifery in Edinburgh. Once fairly fixed in that position, it became the stand-point whence emanated all his subsequent multifarious and brilliant intellectual wcrk. In his own special department I do not presume to be a judge, but I imagine that since the days of Smellie, William Hunter, and Denman, he has never been surpassed. In scholarship, in antiquarian lore, and in extent of practice he has had few equals in our profession; and rarely have men earned such distinction as he did out of their ordinary walk in life. The zeal with which he investigated any subject, professional or otherwise, was unbounded, and it has been, I venture to say, fortunate for modern anæsthesia that Simpson lived. Whilst recognising his remarkable discovery and development of the peculiar influence of chloroform, it may in after time be questioned whether he does not deserve equal if not greater credit for the persistence with which he advocated anæsthesia in woman's most trying hour. Sulphuric ether is still by many thought equal if not superior to chloroform, and other agents are in high repute in surgery and dentistry; but Simpson's practical vigour in anæsthesia has never been surpassed, and his name must always remain associated with one of the most remarkable discoveries connected with our profession. Although Simpson's path was more as a physician than a surgeon, he had remarkable proclivities for surgery.
These were evinced in every imaginable way in his own special department, but chiefly in his discovery, as I may call it, of acupressure, and the remarkable zeal with which he recommended this mode of closing divided arteries. His forensic powers in advocating the advantages of this practice have never, I imagine, been sufficiently appreciated. His abuse of the ligature would have gratified Pare's most violent enemies, and his modern artillery, consisting in suppuration, absorption, blood-poisoning, pyæmia, and secondary deposits might, if used in former times, have blown the doctrines of the great Ambrose into thin air. It was in association with this subject that his powers as a special pleader were remarkably displayed; for here he revived and made to appear in a new and original aspect, under the name of surgical fever, all those doctrines regarding symptomatic, sympathetic, or inflammatory fever, which had been in a manner originated by John Hunter, and elaborated by Thompson, Travers, and others. Yet in regard to these matters, we must claim Simpson as a genuine disciple of Hunter. His object was to further adhesion by the first intention, and to avert constitutional irritation. He entertained the idea that needles were less of foreign material, less offensive to nature, than ligatures. This is neither the time nor opportunity to discuss these in. teresting matters in association with surgery or Simfson's memory, but I cannot resist the opportunity of paying my humble tribute of personal commemoration to one who, in the combined character of physiologist, archæologist, obstetric physician and surgeon, and the giver of the greatest possible good to the greatest possible number, has perhaps never had an equal.

My last tribute in this way shall be in memory of James Syme. Like most who have specially distinguished themselves in surgery, Mr. Syme began his brilliant professional career as a teacher of anatomy. His destiny, however, had been surgery, and he soon relinquished the scalpel of the anatomist for the knife of the surgeon. His success in his newlyassumed duties was remarkable. His zeal, earnestness, and ability were speedily recognised; and although at this time he was comparatively quiet, modest, and of retiring habits, he gained hosts of admirers and friends, who foresaw in him the future chief of surgery in Scotland. He had to work his way, I may say stand his ground, in a department already occupied by distinguished teachers - Allan, Turner, Liston, and Lizars ; yet the numbers of his pupils speedily became nearly as large as those of the whole of his contemporaries. At this period, before taking office in the Royal Infirmary, he, almost on his single responsibility, instituted a small surgical hospital, which he managed in all its departments with prudence and indomitable energy. Cases of special interest were sent to him from all parts of Scotland, which enabled him to display that great diagnostic power, clear judgment, rare manual dexterity, skill in design, and surgical courage, for all of which he afterwards became so distinguished. It was here also that he speedily evinced those remarkable qualities which made him the ablest clinical teacher of surgery of the day. I remember well the effects of his labours on his immediate pupils. He was their prophet in surgery, and inspired them with entire confidence in his powers. The great tact which he had in making a trivial case in surgery appear almost as interesting as one of the most complicated, was remarkable. Although in reality he had a keen relish for all the great things in surgery, he could clothe the story of a carbuncle or a whitlow with the romance of a diseased elbow - a theme rendered at that time, through his individual exertions, of surpassing interest. The migration of Liston to London left Syme on the well-won throne of practical surgery in Edinburgh and Scotland; and how he held sway, and increased his renown, is well known to all who have watched our schools during the last thirty or forty years. There is scarcely a subject in surgery which he has not touched, and thereby adorned. Besides his standard works "On the Principles of Surgery," "On Excision of Diseased Joints," "On Diseases of the Rectum," "On the Pathology and Practice of Surgery," and his remarkable paper on Stricture of the Urethra and Perineal Section, he has written more voluminously in the shape of isolated papers on surgical subjects than any practical man that could readily, perhaps possibly, be named. His operations on the jaws when they were little known in Britain, his revival of excision of the elbow, his special amputation at the ankle-joint, his ingenious plastic operations on the face, his operations on the great arteries for aneurism (on Hunterian principles, and notably on the old principle), and his bold removals of the entire upper extremity, will indelibly associate his name with the grandest deeds in practical surgery with which we are acquainted. Mr. Syme was in every sense an accomplished surgeon. His preliminary education was good; he had knowledge and skill in modern languages, and inborn taste for science and natural history, which he cherished throughout life. But a passion for surgery seemed to dominate in his temperament. Happy for himself that it was so, for it may be justly said that he was king among his fellows; and happy it has been for surgery that such a 
man should have devoted his great abilities to the embellishment of that department of art and science in which the disciples of John Hunter are so deeply interested.

Such themes are apt to attract too much attention from one in my present position. It must be admitted, however, that they were at least the second object of the founders of this ceremony.

Before making my bow of conclusion I shall revert to the memory of the great man in whose honour we are assembled. In as far as we can make out, his life was happy as it was brilliant, and peculiarly so in that he was enabled, without hindrance, to indulge to a greater extent than most men ever did, in a natural, useful bias of mind. His professional gains were estimated by himself chiefly in proportion as they enabled him to pursue his studies and increase his accumulations in natural history; and he gratified his desires in this way to an extent as fabulous as any history records. Men have given thousands for single pictures, or objects of art; but who, excepting John Hunter, enthusiast above all other anatomists, ever paid five hundred pounds for a human skeleton? That his pursuits were more pleasurable to him than any other work in the world must be undoubted. Look at the results. $\mathrm{He}$, in the course of years, and at the age of sixty-five, accumulated a treasury of facts in his Museum and writings, which, from the time of his death to the present day, may be said to have been the fountain-head of modern science in our profession. The streams from thence have flowed in largely varied directions, and no man yet can span the course they may take! Truly his example may excite to emulation. Even the length we may lag behind should induce us to think more highly of the lofty pinnacle where he stands, alone among surgeons! The question between genius and industry is not worth discussion in his case. That he had industry no one can dispute; he has left evidence of it unparalleled among surgeons. I am a firm believer in his genius, but am of opinion that it was so tempered, so overspread, with the spirit of industry, that there was the just balance, so rarely combined in one man, which gives him a pre-eminence among mortals, and a rank in place with the greatest of human beings. He was born, the tenth child of his parents, in a modest country house in Scotland. He seems to have led the idle life of a wayward, petted boy, until twenty years of age, when his action changed, and the dawn of his future greatness appeared. He had neither wealth nor influential friends to further his worldly prospects, yet he rose to be the foremost surgeon and physiologist of his day. He read nature more closely than most other men, and thereby came nearer into communion with the Divine Author of all. Parts of the proof of his physical labour are treasured within these walls ; portions of his mental labour are, in printed form, the property of the world at large ; his mortal remains rest beside those of many of England's greatest sons within the hallowed shrine of Westminster Abbey.

Such is, in brief, the story of John Hunter !

\section{CLINICAL MEMORANDA.}

\section{SCALPED BY BURNING.}

THE case of destruction of the scalp and exfoliation of the outer table of the skull alluded to by Dr. Lowe in the Journal of the 7th Jan., although most interesting, is, I think, completely thrown into the shade by the following case which came under my notice in 1858 when I was practising in Upper Canada. On the 29th October, 1857, an Irishwoman, aged 5o, fell forwards into the fire in an epileptic fit; and, no one coming to her rescue, she remained exposed to the flames till her face and neck were severely injured, and the frontal and parietal bones almost denuded of flesh. My partner, Dr. Salmon, attended her till the severer effects of the accident had become mitigated; I did not see the case myself till ten months had elapsed, and a more horrible disfigurement of the human form I never had witnessed. Large sloughs had come away, leaving the whole calvarium bare and as dead looking as an exhumed skull. Surrounding this extensive surface of denuded skull was the free margin of the uninjured integument of the head, forming a halo of clean and healthy-looking granulations. The much-to-be-dreaded cicatrix - the result of the injury to the chest and neck by the flames-had drawn the chin down to the upper part of the sternum by innumerable fleshy bands. Ectropion of the upper lid, the result of a cicatrix in the integument over the eye, exposed to view that organ itself much injured by the fire; and only sutficient skin was left upon the poor creature's forehead to mark the region of the supercilia. Other scars frightfully marred her form and visage. Mutilated as she was, the poor woman appeared in excellent health and spiritsbright, cheerful, and happy. Upon examining her head, I found that Nature was using her utmost endeavours to throw off the dead bony shell which had so long been deprived of its nutriment and protection. On August 15 th, 1858 , whilst using the mild stimulating lotion which I had ordered, she felt the bone move, and, using a little more additional force, succeeded in lifting off the whole top of her head. I shall not forget my astonishment upon calling to see my Irish patient a few mornings afterwards, when I saw her reach down from the chimney-piece the large piece of exfoliated bone. Her head was done up Turk fashion, in a turban of well greased cloths, upon removing which I exposed an enormous fleshy-looking pulsating tumour, which proved to be the cerebrum covered with its investing membranes. She appeared to suffer little or no pain, and, when I called, was busily employed in knitting stockings. I had to exert all my persuasive powers to get possession of the bone, so convinced was she that, if she once allowed it out of her sight, her head would never heal up. It measured five inches and three-quarter in its longitudinal and four inches and a half in its transverse diameter. Its internal surf $x c_{3}$ e exhibited patches of the inner table of the skull, but the greater portion was exposed diploë. At the earnest request of Dr. Lizars, of Toronto, I presented it to the Pathological Museum in that city, where it may now be seen. Before parting with it, I had it photographed and some engravings taken, which I have now in my possession. I kept my eye upon the patient for several years afterwards, and used frequently to meet her walking into market, a distance of four miles, under the burning rays of the summer sun-in fact, she appeared to suffer little or no inconvenience from her severe loss of personal property. The dura mater seemed to be thickened; otherwise she had, when last I saw her, no other protection to her brain.

In operating upon cicatrices from burns, I found the only plan to adopt to prevent the inevitable drawing together of the parts was to fasten a piece of worsted thread round the limb against the inner part of the wound. This seemed to act as a barrier, over which the granulations would not pass. It kept up irritation all the time in the part. HARveY J. PhilPot, M.D.(Toronto), M.R.C.S.L., late Staff Assist.-Surg. to H.M. Forces in the Crimea.

\section{BROW-AGUE.}

What is brow-ague? A pain in one supraorbital region, recurring periodically, passing away completely, curable by large doses of quinine, might, I suppose, be so designated. Although this pain occurs suspiciously near a well-known nerve-trunk, yet it is, I think, clear that it has but little to do with the supraorbital nerve. If this nerve were neuralgic, the pain should be in its peripheral distribution-that is, on the scalp; whilst it is usually limited to the brow. Then the pain is often under the brow as well as over it. Brow-ague, according to my experience (in part personal), begins as a peculiar and very disagreeable sensation of twisting just beneath the inner third of the eyebrow. It is at first restricted to a patch of the size of a sixpence. Then the pain spreads, and all the brow becomes painful and tender. If the finger be pressed upwards under the orbital roof, it will be found that it also is tender. The pain does not dart upwards into the scalp, or, at any rate, not far. It is much increased by sudden movement of the head, and throbs if the head be held down. Although the periosteum of the affected part certainly seems tender on pressure, yet continued pressure, as is well known, relieves the pain. One cannot, by pressure on the supraorbital nerve-trunk itself, produce pain in the scalp; increase of the local tenderness only is caused. Sometimes there is, I am sure, slight swelling of the affected part. The case from which I describe these symptoms was well characterised. The pain used to begin every morning about nine, last through the day, and quite pass off in the evening. It appeared to be connected with derangement of the stomach and liver, and was finally cured by purgatives and quinine. It occurred, however, in a patient who suffers from transitory attacks of joint-rheumatism, and who inherits tendency both to gout and rheumatism. The phenomena produced seem to me more like local persistent pain induced by nerves than a pure neuralgia. Jonathan Hutchinson, F.R.C.S., Surgeon to the London Hospital.

The Liverpool Medical Missionary Society held its seventh annual meeting on January 3oth. A dispensary, in addition to the one already existing, has been opened in a new locality during the past year. The cases, including new and old, seen and prescribed for at both dispensaries during 1870 , amounted to 72,291 ; and the visits paid to the sick poor at their houses were II,2 IO. Various subsidiary works of benevolence have also been carried on in connection with the dispensary; and a suitable person, combining the offices of Biblewoman and nurse for the sick, has been appointed, and her services have proved of much value. The funds of the society have been sufficient to meet all expenses, so that a new year is entered upon free from debt. 